\title{
Predictability of Visual Processes on Performance in Geometry
}

\author{
Lisa Marie Weckbacher ${ }^{1} \&$ Yukari Okamoto ${ }^{2}$ \\ ${ }^{1}$ Department of Psychology, California State University Channel Islands, Camarillo, California, USA \\ ${ }^{2}$ Gevirtz Graduate School of Education, University of California Santa Barbara, Santa Barbara, California, USA \\ Correspondence: Lisa Marie Weckbacher, Department of Psychology, California State University Channel \\ Islands, One University Drive, Camarillo, California 93012, USA. Tel: 1-805-437-8945.
}

Received: August 8, 2018

Accepted: August 30, $2018 \quad$ Online Published: September 6, 2018

doi:10.5539/jel.v7n6p25

URL: https://doi.org/10.5539/jel.v7n6p25

\begin{abstract}
There is a consensus that certain cognitive abilities and mathematics performance are related. This link also extends to geometry. Surprisingly, however, little research has examined specific aspects of cognition that may contribute to successful performance in geometry, particularly at the secondary level. In this study, we explored in what ways, if any, three types of cognitive abilities (spatial visualization, mental rotation, and imagery ability) and one's preferred cognitive style (a visualizer or verbalizer style) might be related to geometry. High school students who have already taken at least two quarters of geometry participated in the study $(N=114)$. The results showed that the two spatial measures, not cognitive style, were significantly correlated to geometry performance. Of the two spatial measures, paper folding, not mental rotation, emerged as a significant predictor of geometry performance. The interpretations of the current findings as well as educational implications are discussed.
\end{abstract}

Keywords: geometry, spatial visualization, mental rotation, cognitive style, STEM

\section{Introduction}

To maintain a technological edge as an industrialized society, the development of certain abilities that contribute to success in science, technology, engineering and mathematics (STEM) is inarguably in need (Kell \& Lubinski, 2013). Of concern, the US continues to lag behind on average mathematics and science literacy scores, and fails to produce students in the highest levels of mathematics achievement compared to other developed countries (National Science Board, 2016). Geometry - an area of mathematics that is intuitively associated with visualization - tends to be a weaker subject area amongst US students (TIMSS \& PIRLS, 2016). Surprisingly, however, there is a paucity of research on specific aspects of cognition that may contribute toward successful performance in geometry, particularly at the secondary level. In the current study, we explored if certain cognitive abilities (spatial visualization, mental rotation, and imagery ability) and cognitive style (visualizer or verbalizer style) are related to geometry performance.

\subsection{Visualization as a Problem-Solving Tool}

In the words of Mayer (1992), a problem exists when an individual has a goal but does not know how to immediately reach the goal. A problem consists of three states: a given state (i.e., the current state of the situation), a goal state (i.e., the desired state of the situation), and obstacles that prevent the individual from moving directly from the given state to the goal state. Problem solving occurs when it is determined how to solve a problem, that is, successfully moving from the given to the goal state. Studies in mathematical problem solving have shown that the differential use of visualization may or may not lead an individual to the goal state (e.g., Hegarty \& Kozhevnikov, 1999; Presmeg, 1986a, 1986b; van Garderen \& Montague, 2003).

Presmeg's (1986a, 1986b) research marks one of the groundbreaking attempts to better understand the multifaceted nature of visualization as it relates to mathematical problem solving. According to Presmeg, all mathematical problems involve reasoning or logic for their solution; the presence or absence of imagery as a part of the solution is determined by a visual or non-visual method. To identify ways in which high school students use imagery in their visual methods when solving problems, Presmeg conducted a qualitative study of classroom observations coupled with student/teacher interviews. Problems ranged in terms of their mathematical content covering areas relevant to algebra, geometry and trigonometry. Presmeg (1986b) drew attention as to how some types of imagery may be more beneficial than others when solving mathematical problems. Of the 54 participants classified as visualizers, the vast majority relied upon the use of what Presmeg referred to as 
"concrete imagery" in that their solution processes often involved an image or diagram tied to irrelevant details or the introduction of false data.

Further evidence pertaining to a preferential use of a type of imagery as a means to problem solving success has continued to evolve since the work of Presmeg (1985a, 1986b). For example, Hegarty and Kozhevnikoz' (1999) study allowed middle school students to solve a variety of mathematical problems printed on individual cards (e.g., "How many picture frames $6 \mathrm{~cm}$ long and $4 \mathrm{~cm}$ wide can be made from a piece of framing $200 \mathrm{~cm}$ long?") that could involve the use of object or spatial imagery. The results showed that on average, the students solved somewhat less than half of the problems correctly with much variance in their solution strategies. Though not significant at the .05 level ( $p=.056$ to be exact), the use of object imagery negatively correlated with success in mathematical problem solving. Quite the opposite, a significantly positive correlation surfaced between the use of spatial imagery and success in mathematical problem solving. van Garderen and Montague (2003) also investigated differences in the preferential use of imagery but amongst middle school students of varying mathematical ability (i.e., students with learning disabilities, average-achieving students, and gifted students) using a battery of tests partly designed to estimate discrete quantities, and knowledge and use of estimation strategies. The results revealed that the primary use of object imagery favored the solution processes of the students with learning disabilities and the average achievers; the primary use of spatial imagery characterized the gifted students. In other words, various levels of problem solving ability seemed to reflect students' differential use of imagery. That is, successful problem solvers tended to draw on the use of spatial imagery, involving dynamic images that can be transformed or manipulated in some way.

\subsection{Types of Spatial Abilities and Geometry}

Literature regarding how visualization may function as a problem-solving tool seems less likely to target any specific area in mathematics. Often times, studies (e.g., Presemg 1985a, 1986b) largely involve problems that attract the use of object or spatial imagery in a number of ways. Consistent with the ideas of Smith (1964) and Krutetskii (1976), stronger evidence to support the link between the use of imagery and problem-solving performance seems to hold for a limited range of mathematical tasks that do tend to be geometric in some way. For example, classroom activities that involve describing, drawing, constructing and visualizing figures help younger students develop geometric ideas of relative properties (e.g., Battista \& Clements; 1996; Clements \& Sarama, 2000; Clements, Wilson, \& Sarama, 1984; Edens \& Potter, 2007; Kinach, 2012; Smith \& Neumann, 2013). As students progress into advanced areas of mathematics, particularly in high school, the ability to visualize figures is put to greater use when faced with more advanced problems that require transformations and geometric modeling (Kirby \& Boulter, 1999). Ironically so, the literature base tends to considerably narrow as less attention is paid toward this level of performance during later versus earlier years.

Types of spatial abilities have been well researched (e.g., Hermelin \& O'Connor, 1986; Linn \& Petersen, 1985; Lohman, 1996; McGee, 1979); however, some spatial abilities tend to be far more studied than others likely due to their relative importance to certain areas of performance, such as mathematics achievement. Spatial visualization, or the ability to transform a representation into another visual arrangement (Carroll, 1993; Ekstrom et al., 1976), is a type of spatial ability that is naturally associated with geometry. Unlike other mathematical domains, geometry tends to involve various transformations on depicted figures and their configurations of angles, curves and surfaces that are abstracted. For research purposes, the ability to perform such transformations has been classically demonstrated with certain spatial visualization tasks; paper-folding and mental rotations are two popular exemplars. With either task, the main goal is to determine a match between a transformed spatial form (e.g., a folded paper with a punched hole or a three-dimensional block configuration) and its original presentation. Empirically speaking, the general trend of findings is that stronger performance on these tasks tends to positively correlate with problem solving success.

Paper folding can be considered an appropriate measure in finding a relation between types of spatial abilities and success in geometry. Though decades past, in a comprehensive review of the psychometric literature pertaining to spatial abilities, McGee (1979) suggested that success in college mathematics, geometry for one, is linked to the underlying mental process involved in the solution of spatial visualization tasks like paper folding. Prior to McGee, Holzinger and Swineford's (1946) factor analytic study revealed that performance on two paper-folding tasks significantly predicted high school students' achievement in geometry. Years later, Sowder (1974) examined an array of achievement, affective, and cognitive variables hypothesized to differentiate high versus low geometry achievers to varying degrees. Paper-folding performance surfaced as a significant discriminatory variable in favor of the high-achieving group. Connor and Serbin (1980) developed separate mathematics achievement tests for their middle school and high school participants respectively from a battery of standardized items rooted in arithmetic, algebra or geometry. Findings included a significantly positive 
correlation between scores on paper folding and each geometry achievement measure at both the middle school and high school levels. More recently, Pittalis and Christou's (2010) theoretical and empirical breakdown of spatial abilities into distinct factors (i.e., spatial visualization, spatial orientation, spatial relations) revealed their unique contribution to types of three-dimensional geometric thinking. They concluded that performance on spatial visualization tasks, such as paper folding, is a strong predictor of students' problem solving performance albeit in a specific subdomain.

In comparison to paper folding, the ability to mentally rotate two- or three-dimensional figures has been more frequently investigated. When broadly interpreted, findings suggest that mental rotation is a key factor in determining successful problem solving performance in geometry (e.g., Battista, 1990; Casey, Nuttall, Pezaris, \& Benbow, 1995; Battista, Wheatley, \& Talsma, 1982) given both mental rotation and geometry require the ability to process abstract visual stimuli. In addition to, other variables, such as types of geometry measures (i.e., grades versus SAT-M) (Battista, 1999), geometric content (Pandiscio, 1994), mathematics self-confidence and anxiety (Casey, Nuttall, \& Pezaris, 1997), fluid intelligence (Kyttälä \& Lehto, 2008), as well as the ability to retrieve mathematical information stored in long-term memory (Delgado \& Preito, 2004) have been considered in order to more closely capture the strength of this relation. Thus, mental rotation ability likely accounts for some success in geometry, given there is good reason to assume that mental rotation is merely one variable that influences performance in this domain (Weckbacher \& Okamoto, 2014).

One typology of spatial abilities involves a 2 x 2 classification system based on two key dimensions: (1) intrinsic and extrinsic information and (2) static and dynamic tasks (Uttal et al., 2013). Intrinsic information pertains to identifying and defining the characteristics of an object including the spatial configurations against distracting background information. In contrast, extrinsic information pertains to the relations among objects in a group, as well as the overall framework or environment. Static and dynamic tasks specifically relate to the movement of an object. Static tasks refer to when an object remains intact with no transformation in any way; whereas dynamic tasks refer to folding, cutting, or changing an object's position relative to other objects. Taken together, the typology accounts for four types of spatial abilities: intrinsic-static, intrinsic-dynamic, extrinsic-static, and extrinsic-dynamic. For instance, the recognition of a polygon based on its salient geometric properties involves intrinsic, static information; the rotation of the same polygon involves intrinsic, dynamic information. The interpretation of maps that often requires knowledge of length, distance, or angle connects with the extrinsic, static category. In a related context, map interpretation that consists of shifts in spatial relations, such as searching for and locating hidden objects, exemplifies an extrinsic-dynamic spatial ability. In general, all four categories of spatial abilities are considered to be malleable, and that appropriate training can be effective, durable and transferrable. Both paper folding and mental rotation fall into the intrinsic-dynamic category of spatial abilities.

\subsection{Cognitive Style}

An individual's cognitive style refers to "information-processing habits" representing distinct ways of perceiving, thinking, remembering and problem solving (Green \& Schroeder, 1990). It is not considered a capability (Mayer \& Massa, 2003), but rather a unique predictor of performance (Kozhevnikov, 2007). The study of cognitive styles dates back to the 1970's, at which time Richardson (1977) proposed that individuals can be classified as either verbalizers or visualizers, more formally known as the verbalizer-visualizer dimension. Theoretically, the left end of the dimension represents a verbal mode of thought; the right end represents a visual mode of thought. Individuals who primarily process information through the use of language symbols are considered to be high-verbal and low-visual, or simply verbalizers. Individuals who are high- visual and low-verbal, also referred to as visualizers, rely upon types of visual information when performing a cognitive task.

Closer examination of visualizers' strengths in problem solving situations has led researchers to identify different styles in visual imagery: object imagery and spatial imagery (e.g., Blajenkova, Motes, \& Kozhevnikov; 2006; Kawahara \& Matsuoka, 2013; Kozhevnikov, Hegarty, \& Mayer, 1999, 2002; Kozhevnikov, Kosslyn, \& Shephard, 2005). An object visualizer is drawn to static images, and pays more attention to shape and color, as well as size and brightness; a spatial visualizer prefers to manipulate images, and is more likely to process location, movement, spatial relations and transformations (Kawahara \& Matsuoka, 2013). This line of thinking is consistent with research in neuroscience and cognitive psychology that refutes the conception of visualization as a general or undifferentiated construct, but rather, it consists of two dissociable visualization systems. One line of evidence (Kosslyn et al., 1990) shows how each system, though sharing some common mechanisms, independently allows for distinct object and spatial components of a mental image. As observed in one experiment, when participants visualized faces or colors, neuroimaging results showed activation of the temporal lobes. On the other hand, when participants visualized a route on a map that they had previously memorized, 
results showed activation of the parietal lobes (Uhl, Goldenberg, Lang, \& Lindinger, 1990). Both cognitive styles have been linked to life outside the laboratory setting. For instance, visual artists tend to be object visualizers, whereas scientists and engineers tend to be spatial visualizers (Kozhevnikov, Kozhevnikov, Yu, \& Blazhenkova, 2013).

\subsection{Research Question}

Although research has shown that types of visual processes tend to be conducive to problem solving success (e.g., Hegarty \& Kozhevnikov, 1999; Presmeg, 1986a, 1986b), the scope of those findings applies to a broader range of mathematical problems as opposed to a specific mathematical domain. In our study, we investigated if certain visual processes are more likely to predict performance in geometry. To the best of our knowledge, the relation amongst cognitive abilities (i.e., spatial visualization, mental rotation, and imagery ability) and cognitive style (i.e., a visualizer or verbalizer style) with respect to geometry performance has yet to be explored. Thus, in this study we set out to address the following question: Is the role of cognitive ability different from cognitive style with respect to geometric problem solving?

\section{Method}

\subsection{Participants}

A total of 114 students (56 females) from a private high school in northeastern Pennsylvania participated in the study. The school is located in an urban, middle-class area that predominantly consisted of a Caucasian, English-speaking population. Based upon the demographics of the school's population, all of the students who participated spoke fluent English. The mean age of the total sample was 16.98 years $(S D=.74)$; for males and females, their mean ages were 17.00 years $(S D=.76)$ and 16.95 years $(S D=.73)$ respectively.

According to the school's mathematics curriculum, geometry is a required full-year course of study typically undertaken in $10^{\text {th }}$ grade. To be included in the current study, students must have completed a minimum of two academic quarters or approximately 6 months of study in geometry by the date of testing. This criterion served to assure that each participant had been exposed to problem solving involving geometric content at the high school level. The vast majority of $10^{\text {th }}$ -, $11^{\text {th }}$ - and $12^{\text {th }}$-grade students were therefore eligible to participate.

Recruiting participants took place during $10^{\text {th }}$ - $11^{\text {th }}$ - and $12^{\text {th }}$-grade mathematics classes. To initiate the process, the head of the mathematics department asked students who satisfied the above criterion to participate in a university-based "mathematics project" that focused on problem solving ability. Faculty members from the mathematics department assisted in the distribution and collection of parental permission forms to all eligible students.

\subsection{Measures}

We used three tests of cognitive abilities: Paper Folding, Mental Rotations Test and the Snowy Pictures Test. As a measure of cognitive style, the Verbalizer-Visualizer Questionnaire was used. To assess students' geometric problem performance, we developed a test using existing test items. Details are provided below.

\subsubsection{Spatial Visualization Ability}

The Paper Folding Test (PFT) consisted of 10 items. The full-scale version of this test consists of two parts, but only Part 1 was used given time constraints for the administration of all measures. Each item illustrates successive drawings of two or three folds made in a two-dimensional representation of a square sheet of paper. The last drawing shows a punched hole in the folded paper. For each item, the goal is to correctly select one of five drawings showing how the paper will appear when fully opened. The total number of correct items determines the score. Aside from the standard instructions, total time for completion is 3 minutes for all 10 items. Ekstrom et al. (1976) reported that the test-retest reliability was .84. For this study, the Chronbach's alpha coefficient was .70.

\subsubsection{Mental Rotation Ability}

The Mental Rotations Test (MRT) (Vandenberg \& Kuse, 1978) consisted of 10 items. The full-scale version of this paper-pencil test consists of two parts, but for present purposes, only Part 1 was used. Each item is a three-dimensional configuration of 10 blocks. The goal for each item is to determine a match between a primary configuration of blocks and two of four configurations rotated in different positions. Scoring was done according to the original method; two credits are awarded if the two items chosen are correct or one credit if only one item is chosen and correct. No credit is awarded if two items are chosen but only one is correct. In addition to the standard instructions, total time for completion is 5 minutes for all 10 items. Vandenberg and Kuse reported that the Kuder-Richardson 20 coefficient was .88. In the current study, the Chronbach's alpha coefficient was .72. 


\subsubsection{Imagery Ability}

The Snowy Pictures Test (SPT) (Ekstrom et al., 1976) measures object imagery by detecting simple objects or pictures hidden within complex patterns of visual noise. Standardized instructions precede this two-part test consisting of 12 black and white items within each part. Both parts of the test were administered, 24 items in all. The score is the overall number of items identified correctly. Six minutes, or 3 minutes for each part, is the total time allotted to complete all items. The Cronbach's alpha coefficient was .59 in this study. Previous reports of internal consistency had not been found for the original version of the SPT to compare.

\subsubsection{Cognitive Style}

The Verbalizer-Visualizer Questionnaire, or the VVQ (Richardson, 1977), is a commonly used measure of verbal-visual cognitive style (i.e., thinking in terms of words or pictures) by rating the use of imagery in everyday type thinking. The questionnaire consists of 15 items in total: eight pro-visual statements and seven pro-verbal statements. Mayer and Massa (2003) altered the response format from true-false to a 7-point Likert-type scale with a Cronbach's alpha of .71. For the current study, the VVQ was further altered to a 6-point Likert-type scale to avoid "neither agree or disagree" as a frequent response. In this way, students were forced to consider one side or the other across a condensed continuum of choices rating each statement with $6=$ strongly agree and $1=$ strongly disagree; ratings 5 through 2 indicated intermediate degrees of agreement-disagreement. Of the 15 statements, 6 are negatively formulated (4 visual and 2 verbal), and therefore, were reversely scored (e.g., $1=$ strongly agree). A participant's total VVQ score was based upon the average weight of pro-visual ratings minus the average weight of pro-verbal ratings given the unequal number of statements in each classification (i.e., 8 visual, 7 verbal). A positive total score indicates a stronger association with visual rather than verbal experiences. The total time to complete the questionnaire was not to exceed 10 minutes. The Cronbach's alpha coefficients for this altered version of the VVQ was .78.

\subsubsection{Geometric Problem Solving}

The 20 questions for the Figural Geometry Measure (FGM) were drawn from NAEP's (2006) standardized item pool intended to gauge what US students know and can do in geometry at the 4th-, 8th-, and 12th-grade levels. The selection of items was based upon the National Council of Teachers of Mathematics (2000) and the Pennsylvania Department of Education's (2003) academic standards in geometry.

FGM items reflected a wide range of ability with easier to more difficult items representative of each grade level pool (see Appendix for sample items). Item selection depended upon the use of an illustrated or mentally constructed three-dimensional or two-dimensional figure to solve a problem. Any standardized item that strongly resembled a spatial test item, such as letter rotation, was avoided in order to maintain consistency with what each measure in this study assessed. Question format was either a multiple choice or short-constructed response totaling a possible 20 points with one point awarded for each correct answer. Given that the instructions specifically state not to skip any problems, no credit was awarded for any missed item, and therefore, scored as zero. The total time for the completion of all 20 items was not to exceed 30 minutes. The Cronbach's alpha coefficient for the FGM was .69.

To provide a variety of items across measures, the order of administration was as follows: (1) PFT, (2) SPT, (3) MRT, (4) VVQ, and the (5) FGM. All data were collected over the course of three school days, and students were welcomed to contact the principal investigator regarding the results of their individual and class performance shortly thereafter.

\section{Results}

Descriptive statistics as well as Pearson correlation coefficients are presented in Table 1. Three correlation coefficients were statistically significant. First, as expected, the two measures of spatial abilities, the MRT and the PFT, were significantly correlated $(r=.27, p=.004)$. The two other significant correlations were found between the FGM and each of the two spatial measures: PFT $(r=.26, p=.006)$ and MRT $(r=.23, p=.014)$. No other correlations were statistically significant. The VVQ and the SPT were negatively correlated $(r=-.17)$ but did not reach significance $(p=.065)$. Although not statistically significant, the direction of the correlation (i.e., negative) suggests that object imagery is associated more with a verbal cognitive style. Higher scores on the VVQ point to a preference for a visual style. 
Table 1. Descriptive statistics and correlation coefficients

\begin{tabular}{llllll}
\hline Measure & 1 & 2 & 3 & 4 & 5 \\
\hline 1. PFT & & & & & \\
2. MRT & $.27^{* *}$ & & & \\
3. SPT & .18 & .09 & -.17 & & \\
$4 . \mathrm{VVQ}$ & .12 & -.01 & .11 & .11 & 15.11 \\
$5 . \mathrm{FGM}$ & $.26^{* *}$ & $.23^{*}$ & 11.21 & 5.50 & 2.99 \\
$M$ & .68 & 14.71 & 4.94 & 2.03 & .69 \\
$S D$ & .81 & 3.01 & .71 & .70 & \\
Cronbach's $\alpha$ & .78 & .59 &
\end{tabular}

Note. $\mathrm{SPT}=$ Snowy Pictures Test. MRT= Mental Rotations Test. PFT $=$ Paper Folding Test. FGM = Figural Geometry Measure.

$* \mathrm{p}<.05$, two-tailed. $* * \mathrm{p}<.01$, two-tailed.

Taken together, the significant correlations between the FGM and each of the spatial measures suggest that PFT and MRT are potential predictors of geometric performance. In order to find the best set of predictors, we ran several regression analyses. The results are shown in Table 2. Model 1 resulted from a stepwise procedure. When all variables were entered into the equation, only PFT was found to be a significant predictor of FGM. To examine if the inclusion of MRT adds to PFT, we used a forced method to enter MRT after PFT. This is Model 2. Model 2 slightly improved the overall predictive power. However, the $F$ change in $R^{2}$ was not significant. Because these two spatial measures were significantly correlated, PFT was able to account for most of the variances explained.

Table 2. Regression analyses: model summary

\begin{tabular}{ccccccccc}
\hline Measure & $B$ & $S E B$ & $\beta$ & $t$ & $F$ & $p$ & $R^{2}$ & $F$ change \\
\hline Model 1 & & & & & $7.99(1,112)$ & .006 & .07 & $7.99^{*}$ \\
PFT & .38 & .13 & .26 & 2.83 & & .006 & & 3.46 \\
Model 2 & & & & & $5.81(2,111)$ & .004 & .10 & \\
PTF & .31 & .14 & .21 & 2.26 & & .026 & & \\
MRT & .11 & .06 & .17 & 1.86 & & .065 & &
\end{tabular}

\section{Discussion}

\subsection{Overview of Findings}

The current study set the stage to identify how select visual processes contribute to students' performance in geometry. Overall, the results suggested that in contrast to cognitive style, spatial abilities are more likely to be instrumental in problem-solving success.

Consistent with previous findings that have used the same or similar types of spatial visualization tests (e.g., Blajenkova et al., 2006; Kozhevnikov et al., 2002; van Garderen, 2006), the PFT and the MRT correlated positively and significantly with one another. In line with Uttal et al.'s (2013) typology of spatial abilities that classifies spatial thinking into four distinct categories, paper folding and mental rotation are considered intrinsic-dynamic abilities that involve the ability to spatially transform given objects, and therefore the reported correlation was expected. On the other hand, we employed the VVQ and the SPT as our measures of cognitive style and imagery ability. The VVQ is a well-established assessment tool that purports to identify an individual's preference toward verbal or visual processing. Although findings have led researchers to raise questions regarding the reliability and validity of this measure (Antonietti \& Giorgetti, 1996; Boswell \& Pickett, 1991; Green \& Shroeder, 1990), it continues to be widely used as one way of determining how verbal and visual learning styles are qualitatively distinct from one another (e.g., Knoll, Otani, Skeel, \& Van Horn, 2017; Pazzaglia \& Moè, 2013). In a relatively recent study on cognitive style and mental rotation in map learning (Pazzaglia \& Moè, 2013), the findings revealed a non-significant negative correlation between the VVQ and the SPT, quite similar to the correlation in the current study. Considering the content of the items on the VVQ, the relation between the VVQ and the SPT makes sense. The visual items on the altered version of the VVQ that had been used in this study are a combination of items partly rooted in the experience of dreams (e.g., "I seldom dream." and "My dreams are extremely vivid."). In contrast, the SPT is a measure of object imagery, a type of visual style that involves the ability to develop and recognize holistic mental images, typically in the form of a 
familiar object, which bears little if any relation to the experience of dreaming.

The significantly positive correlations between each spatial visualization measure and the FGM are consistent with previous findings that specifically focus on the role of paper folding and/or mental rotation as they pertain to student success in mathematics achievement. For example, Weckbacher and Okamoto (2014) found that high school students with stronger mental rotation ability tended to be stronger in geometry achievement. Albeit with a gifted sample of participants who had scored within the top .5\% on SAT tests, Lubinski and Benbow (2006) concluded that participants who pursued STEM majors and later held STEM careers exhibited talent in mental rotation as early as age 13. Unlike previous studies, however, Cromley et al. (2017) compared the relative predictive value of mental rotation to paper folding. After accounting for the degree of shared variance between the two tasks, mental rotation emerged as a unique predictor of performance on AP calculus exam questions, which tend to reflect AP textbook content and respective classroom instruction. In contrast, paper folding emerged as the significant predictor of performance on our mathematics achievement measure, the FGM. Whereas Cromley et al. asserted that spatial abilities with "rigid transformations" (i.e., the block figure does not change shape) and multistep representations tend to be related to calculus proficiency, we can similarly conclude that the type of spatial abilities needed to successfully solve the items on the FGM do not necessarily require the same or perhaps similar abilities. In other words, the visual process(es) needed to solve the items on the FGM may be more closely aligned to paper folding rather than mental rotation tasks.

\subsection{Educational Implications}

According to Wheatley (1997), imagery had not been recognized as playing an important role in mathematics due to the overemphasis on learning and using rules that tend to make little sense to learners. In subsequent years, there has been a considerable shift in regards to the study of imagery, and other visual processes, relative to artistic or scientific creativity (Kozhevnikov et al., 2013) as well as problem solving across related disciplines (Anderson et al., 2008; Cromley et al., 2017; Kozhevnikov et al., 1999; van Garderen, 2006). However, many teachers are likely unaware that instructing students to simply visualize information (e.g., diagrams, pictures, graphs) as a cognitive strategy would probably not be effective. Advancing teachers' knowledge of the efficacy of visualization as it relates to types of visual processes might help all students become better problem solvers in a number of areas. Perhaps as a starting point, students should be encouraged to mentally construct spatial (i.e., location, movement, transformations) rather than object (i.e., shape, color, size, brightness) representations in order for them to obtain a clearer idea as to why certain elements of a problem are more crucial than others (Kozhevnikov et al., 1999; 2002). Keeping in mind that cognitive style has been shown to reflect individual preference rather than performance in problem-solving situations (Kolöffel, 2012), this approach is especially relevant for students who tend to be weak in spatial thinking, and therefore, are more likely to focus their attention on the irrelevant details of a problem at hand.

Thus, improving students' spatial visualization, and mental rotation ability, may be a step toward enhancing performance in geometry, which could lead to greater interest and confidence in higher-level mathematics courses that serve as a gateway to STEM-oriented careers (Hossain \& Robinson, 2012). Despite the demand, in a given year, less than half of the bachelor's degrees awarded in the US pertain to science and engineering fields, which may be linked to students' less than "proficient" performance in mathematics assessments (National Science Foundation, 2014). In addition, unlike students whose academic strengths relate more to general abilities in mathematical and verbal reasoning, students who may be considered spatially talented tend to go unrecognized in modern educational practice (Kell \& Lubinski, 2013).

\subsection{Limitations and Suggestions for Future Research}

There are a few limitations in this study to consider. One pertains to the sole use of Snowy Pictures to measure object imagery. As in Kozhevnikov et al. (2002; 2005), both quantitative and qualitative measures served to detect an individual's preferred mode of object rather than spatial imagery in problem-solving situations. The potential for sampling bias must also be considered. Students who participated were not selected randomly, but rather, chosen solely on their willingness to participate. The students had been recruited from a private school as well, which limits the generalizability of the study's findings to high school students at large. In a related vein, differences in geometry curricula and corresponding instructional practices may more or less emphasize exposure to various subtopics (e.g., 2D versus 3D geometric problem solving). As a result, the probability to discover any meaningful relations across cognitive styles and spatial abilities may be affected by the quality of students' problem-solving experiences within this domain. The results of the current study showed that the use of spatial visualization is related to performance in geometry. These findings contribute toward a growing knowledge base of what seems to constitute success in geometry at the secondary level. However, the strength of 
the respective correlations among the spatial visualization, mental rotation and geometry measures indicated that these associations are not strong. There is a considerable degree of variance that is unexplained, and on that note, it is necessary to consider the potential influence of other variables. By doing so, researchers may be even closer to explaining why so many students struggle in geometry compared to other areas of mathematics.

Although the results of this study provided evidence to answer each of the questions posed, they also gave birth to new ones. These include: (1) In what ways do differences in visual processing relate to instructional practices specific to the spatial aspects of mathematics at the secondary level? (2) How does developing intrinsic-dynamic spatial abilities as part of classroom instruction relate to geometry performance amongst high school students? Research has shown that educational interventions to improve spatial thinking tend to be more successful with young children compared to adolescents and adults, but few if any studies exist to compare developmental differences across age groups (Uttal et al., 2013). However, there is a good deal of evidence to suggest that spatial abilities respond to training beyond the childhood years (e.g., Patkin \& Dayan, 2013; von Károlyi, 2013). In other words, "spatial education is possible in some form at all ages" (Newcombe \& Stieff, 2012, p. 965). That being said, instructional efforts to improve students' geometry performance at the secondary level should consider visualization as a heterogeneous construct that warrants particular attention to students' spatial strengths as well as their deficits.

\section{References}

Anderson, K. L., Casey, M. B., Thompson, W. L., Burrage, M. S., Pezaris, E., \& Kosslyn, S. M. (2008). Performance on middle school geometry problems with geometry clues matched to three different cognitive styles. Mind, Brain, and Education, 2(4), 188-197. https://doi:10.1111/j.1751-228X.2008.00053.x

Antonietti, A., \& Giorgetti, M. (1996). A study of some psychometric properties of the verbalizer-visualizer questionnaire. Journal of Mental Imagery, 20(3\&4), 59-68.

Battista, M. T. (1990). Spatial visualization and gender differences in high school geometry. Journal for Research in Mathematics Education, 21(1), 47-60.

Battista, M. T. (1999). Geometry results from the Third International Mathematics and Science Study. Teaching Children Mathematics, 5(6), 367-373.

Battista, M. T., \& Clements, D. H. (1996). Students' understanding of three-dimensional rectangular arrays of cubes. Journal for Research in Mathematics Education, 27(3), 258-292. https://doi:10.2307/749365

Battista, M. T., Wheatley, G. H., \& Talsma, G. (1982). The importance of spatial visualization and cognitive development for geometry learning in preservice elementary teachers. Journal for Research in Mathematics Education, 13(5), 332-340. https://doi:10.2307/749007

Blajenkova, O., Kozhevnikov, M., \& Motes, M. A. (2006). Object-spatial imagery: A new self-report imagery questionnaire. Applied Cognitive Psychology, 20, 239-263. https://doi:10.1002/acp.1182

Boswell, D. L., \& Pickett, J. A. (1991). A study of the internal consistency and factor structure of theVerbalizer-Visualizer Questionnaire. Journal of Mental Imagery, 15(3\&4), 33-36.

Carroll, J. B. (1993). Human cognitive abilities: A survey of factor-analytic studies. New York: Cambridge University Press.

Casey, M. B., Nuttall, R. L., \& Pezaris, E. (1997). Mediators of gender differences inmathematics college entrance test scores: A comparison of spatial skills with internalized beliefs and anxieties. Developmental Psychology, 33(4), 669-680. https://doi:10.1037/0012-1649.33.4.669

Casey, M. B., Nuttall, R. L., Pezaris, E., \& Benbow, C. P. (1995). The influence of spatial ability on gender differences in mathematics college entrance test scores across diverse samples. Developmental Psychology, 31(4), 697-705. https://doi:10.1037/0012-1649.31.4.697

Clements, D. H., \& Sarama, J. (2000). Young children's ideas about geometric shapes. Teaching Children Mathematics, 6(8), 482-488.

Clements, D. H., Wilson, D. C., \& Sarama, J. (2004). Young children's composition of geometric figures: A learning trajectory. Mathematical Thinking and Learning, 6(2), 163-184.

Connor, J. M., \& Serbin, L. A. (1980). Mathematics, visual-spatial ability and sex roles. Final report. Washington DC: National Institute of Education. (ERIC Document Reproduction Service No. ED205385) 
Cromley, J. G., Booth, J. L., Willis, T. W., Chang, B. L., Tran, N., MAdeja, M., ... Zahner, W. (2017). Relation of spatial skills to calculus proficiency: A brief report. Mathematical Thinking and Learning, 19(1), 55-68. https://doi:10.1080/10986065.2017.1258614

Delgado, A. R., \& Prieto, G. (2004). Cognitive mediators and sex-related differences in mathematics. Intelligence, 32(1), 25-32. https://doi:10.1016/S0160-2896(03)00061-8

Edens, K., \& Potter, E. (2007). The relationship of drawing and mathematical problem solving: "Draw for Math" tasks. Studies in Art Education: A Journal of Issues and Research in Art Education, 48(3), 282-298.

Ekstrom, R. B., French, J. W., \& Harman, H. H. (1976). Manual for kit of factor-referenced cognitive tests. Princeton, NJ: Educational Testing Service.

Green, K. E., \& Schroeder, D. H. (1990). Psychometric quality of the Verbalizer-Visualizer Questionnaire as a measure of cognitive style. Psychological Reports, 66(3), 939-945. https://doi:10.2466/PR0.66.3.939-945

Hegarty, M., \& Kozhevnikov, M. (1999). Types of visual-spatial representations and mathematical problem solving. Journal of Educational Psychology, 91(4), 684-689. https://doi:10.1037/0022-0663.91.4.684

Hermelin, B., \& O'Connor, N. (1986). Spatial representations in mathematically and artistically gifted children. British Journal of Educational Psychology, 56, 150-157. https://doi:10.1111/j.2044-8279.1986.tb02656.x

Holzinger, K. J., \& Swineford, F. (1946). The relation of two bi-factors to achievement in geometry and other subjects. Journal of Educational Psychology, 37(5), 257-265. https://doi:10.1037/h0053536

Hossain, M. M., \& Robinson, M. G. (2012). How to motivate US students to pursue STEM (science, technology, engineering and mathematics) careers. US-China Education Review A, 4, 442-451.

Kawahara, M., \& Matsuoka, K. (2013). Object-spatial imagery types of Japanese college students. Psychology, 4(3), 165-168. https://doi:10.4236/psych.2013.43024

Kell, H. J., \& Lubinski, D. (2013). Spatial ability: A neglected talent in educational and occupational settings. Roeper Review, 35, 219-230. https://doi:10.1080/02783193.2013.829896

Kinach, B. (2012). Fostering spatial vs. metric understanding in geometry. Mathematics Teacher, 105(7), 534-540.

Kirby, J. R., \& Boulter, D. R. (1999). Spatial ability and transformational geometry. European Journal of Psychology of Education, 14(2), 283-29. https://doi:10.1007/BF03172970

Knoll, A. R., Otani, H., Skeel, R. L., \& Van Horn, K. R. (2017). Learning style, judgments of learning, and learning of visual and verbal information. British Journal of Psychology, 108(3), 544-563. https://doi:10.1111/bjop.12214

Kollöffel, B. (2012). Exploring the relation between visualizer-verbalizer cognitive styles and performance with visual or verbal learning material. Computers \& Education, 58, 697-706. https://doi:10.1016/j.compedu.2011.09.016

Kosslyn, S. M., Ganis, G., \& Thompson, W. L. (1990). Mental imagery: Against the nihilistic hypothesis. Trends in Cognitive Science, 7(3), 109-111. https://doi:10.1016/S1364-6613(03)00025-1

Kozhevnikov, M. (2007). Cognitive styles in the context of modern psychology: Toward an integrated framework of cognitive style. Psychological Bulletin, 133(3), 464-481. https://doi:10.1037/0033-2909.133.3.464

Kozhevnikov, M., Hegarty, M., \& Mayer, R. (1999). Students' use of imagery in solving qualitative problems in kinematics. Washington DC: US Department of Education. (ERIC Document Reproduction Service No. ED433239)

Kozhevnikov, M., Hegarty, M., \& Mayer, R. E. (2002). Revising the visualizer-verbalizer dimension: Evidence for two types of visualizers. Cognition and Instruction, 20(1), 47-77. https://doi:10.1207/S1532690XC120001_3

Kozhevnikov, M., Kosslyn, S., \& Shephard, J. (2005). Spatial versus object visualizers: A new characterization of visual cognitive style. Memory \& Cognition, 33(4), 710-726. https://doi:10.3758/BF03195337

Kozhevnikov, M., Kozhevnikov, M., Yu, C., \& Blazhenkova, O. (2013). Creativity, visualization abilities, and visual style. British Journal of Educational Psychology, 83, 196-209. https://doi:10.1111/bjep.12013

Krutetskii, V. A. (1976). The psychology of mathematical abilities in schoolchildren. Chicago: University Press. 
Kyttälä, M., \& \& Lehto, J. E. (2008). Some factors underlying mathematical performance: The role of visuospatial working memory and non-verbal intelligence. European Journal of Psychology of Education, 23(1), 77-94.

Linn, M. C., \& Petersen, A. C. (1985). Emergence and characterization of sex differences in spatial ability: A meta-analysis. Child Development, 56, 1479-1498. https://doi:10.2307/1130467

Lohman, D. F. (1996). Spatial ability and G. In I. Dennis \& P. Tapsfield (Eds.), Human abilities: Their nature and assessment (pp. 97-116). Hillsdale, NJ: Erlbaum.

Lubinski, D., \& Benbow, C. P. (2006). Study of mathematically precocious youth after 35 years: Uncovering antecedents for the development of math-science expertise. Perspectives on Psychological Science, 1 , 316-345. https://doi:10.1111/j.1745-6916.2006.00019.x

Mayer, R. E. (1992). Thinking, problem solving, cognition (2nd ed.). New York: W. H. Freeman.

Mayer, R. E., \& Massa, L. J. (2003). Three facets of visual and verbal learners: Cognitive ability, cognitive style, and learning preference. Journal of Educational Psychology, 95(4), 833-846. https://doi:10.1037/0022-0663.95.4.833

McGee, M. G. (1979). Human spatial abilities: Psychometric studies and environmental, genetic, hormonal, and neurological influences. Psychological Bulletin, 86(5), 889-918. https://doi:10.1037/0033-2909.86.5.889

National Assessment of Educational Progress. (2006). NAEP questions: The nation's report card, [Data file]. Available from National Center for Education Statistics Web site, http://nces.ed.gov/nationsreportcard/ITMRLS/

National Council of Teachers of Mathematics. (2000). Principles and standards for school mathematics. Reston, VA: Author.

National Science Board (2016). Science and engineering indicators 2016: A broad base of quantitative information on the U.S. and international science and engineering enterprise. Retrieved from National Science Foundation's website, https://www.nsf.gov/statistics/2016/nsb20161/\#/

National Science Foundation (2014). STEM education data: College. Retrieved from National Science Foundation's website, https://nsf.gov/nsb/sei/edTool/explore.html\#college

Newcombe, N. S., \& Stieff, M. (2012). Six myths about spatial thinking. International Journal of Science Education, 34(6), 955-971. https://doi:10.1080/09500693.2011.588728

Patkin, D., \& Dayan, E. (2013). The intelligence of observation: Improving high school students' spatial ability by means of intervention unit. International Journal of Mathematical Education in Science and Technology, 44(2), 179-195. https://doi:10.1080/0020739X.2012.703335

Pazzaglia, F., \& Moé, A. (2013). Cognitive styles and mental rotation in map learning. Cognitive Processing, 14, 391-399. https://doi:10.1007/s10339-013-0572-2

Pennsylvania Department of Education. (2003, January 7). Academic standards formathematics (chap. 4). Retrieved from http://www.pde.state.pa.us/k12/lib/k12/MATH.pdf

Pittalis, M., \& Christou, C. (2010). Types of reasoning in 3D geometry thinking and their relation with spatial ability. Educational Studies in Mathematics, 75, 191-212. https://doi:10.1007/s10649-010-9251-8

Presmeg, N. C. (1986a). Visualization and mathematical giftedness. Educational Studies in Mathematics, 17, 297-311.

Presmeg, N. C. (1986b). Visualization in high school mathematics. For the Learning of Mathematics, 6, 42-46.

Richardson, A. (1977). Verbalizer-visualizer: A cognitive style dimension. Journal of Mental Imagery, 1, 109-126.

Smith, I. A. (1964). Spatial ability: Its educational and social significance. London: University Press.

Smith, P. S., \& Neumann, M. D. (2014). Scratch it out! Enhancing geometrical understanding. Teaching Children Mathematics, 21(3), 185-188.

Sowder, L. (1974). High versus low geometry achievers in the NLSMA-Y population. Journal for Research in Mathematics Education, 5(1), 20-27. https://doi:10.2307/748718

TIMSS \& PIRLS. (2016). TIMSS advanced 2015 international results in advanced mathematics and physics. Retrieved from TIMSS \& PIRLS International Study Center website, 
http://timssandpirls.bc.edu/timss2015/international-results/advanced/timss-advanced-2015/mathematics/ach ievement-in-content-and-cognitive-domains/

Uhl, F., Goldenberg, G., Lang, W., \& Lindinger, G. (1990). Cerebral correlates of imagining colours, faces and a map - II. Negative cortical DC potentials. Neuropsychologia, 28(1), 81-93. https://doi:10.1016/0028-3932(90)90088-6

Uttal, D. H., Meadow, N. G., Newcombe, N. S., Tipton, E., Hand, L. L., Alden, A. R., \& Warren, C. (2013). The malleability of spatial skills: A meta-analysis of training studies. Psychological Studies, 139(2), 352-402. https://doi:10.1037/a002844

van Garderen, D. (2006). Spatial visualization, visual imagery, and mathematical problem solving of students with varying abilities. Journal of Learning Disabilities, 39(6), 596-506.

van Garderen, D., \& Montague, M. (2003). Visual-spatial representation, mathematical problem solving and students of varying abilities. Learning Disabilities Research and Practice, 18(4), 246-254. https://doi:10.1111/1540-5826.00079

Vandenberg, S. G., \& Kuse, A. R. (1978). Mental rotations: A group test of three-dimensional spatial visualization. Perceptual and Motor Skills, 47, 599-604. https://doi:10.2466/pms.1978.47.2.599

von Károlyi, C. (2013). From Tesla to Tetris: Mental rotation, vocation, and gifted education. The Roeper Institute, 35, 231-240. https://doi:10.1080/02783193.2013.829547

Weckbacher, L. M., \& Okamoto, Y. (2014). Mental rotation in relation to self-perceptions of high school geometry. Learning and Individual Differences, 30, 58-63. https://doi:10.1016/j.lindif.2013.10.007

Wheatley, G. H. (1997). Reasoning with images in mathematical activity. In L. D. English (Ed.), Mathematical reasoning: Analogies, metaphors, and images (pp. 281-297). Mahwah, NJ: Erlbaum.

\section{Appendix}

Sample Items from the Figural Geometry Measure

\section{Look at the triangles below.}

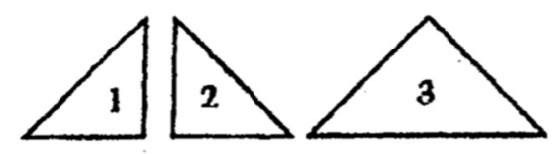

Triangles 1, 2, and 3 shown above can be rearranged with no overlap to form either of the following figures.
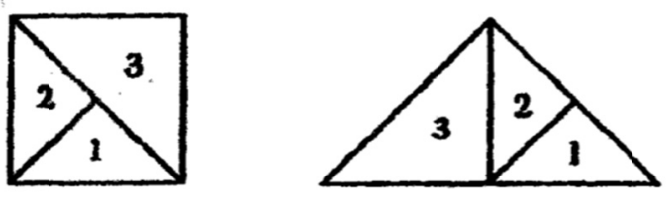

Draw lines on the figure below to show how triangles 1,2, and 3 can be rearranged without overlap to form this rectangle. 
14. In the figure below, points $A, E$, and $H$ are on a plane that intersects a right prism. What is the intersection of the plane with the right prism?
A) A line
B) A triangle
C) A quadrilateral
D) A pentagon
E) A hexagon

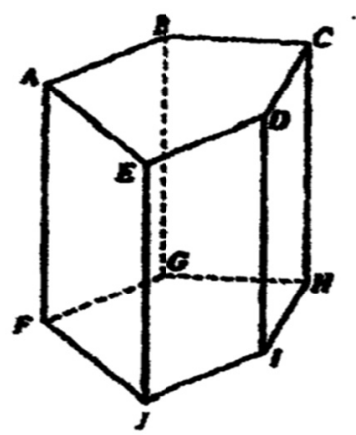

\section{What is the greatest number of squares with 9-inch sides that can be cut from a rectangular piece of cloth 18 inches by 36 inches?}

\section{Answer.}

\section{Copyrights}

Copyright for this article is retained by the authors, with first publication rights granted to the journal.

This is an open-access article distributed under the terms and conditions of the Creative Commons Attribution license (http://creativecommons.org/licenses/by/4.0/). 